\title{
Antibiotic Resistance and Prevalence of Campylobacter jejuni and Campylobacter coli in Poultry Liver
}

\author{
Ali Saadatmand ${ }^{1}$, Mohammad Yousef Alikhani ${ }^{2, *}$, Reza Habibipour ${ }^{3}$, Ali Heshmati ${ }^{4}$ \\ ${ }^{1}$ MSc in Microbiology, Hamadan Branch, Islamic Azad University, Hamadan, Iran \\ ${ }^{2}$ Professor, Brucellosis Research Center, Hamadan University of Medical Sciences, Hamadan, Iran \\ ${ }^{3}$ Assistant Professor, Department of Microbiology, School of Basic Sciences, Hamadan Branch, Islamic Azad University, \\ Hamadan, Iran \\ ${ }^{4}$ Associate Professor, Nutrition Health Research Center, Hamadan University of Medical Sciences, Hamadan, Iran
}

* Corresponding Author: Mohammad Yousef Alikhani, Brucellosis Research Center, Hamadan University of Medical Sciences, Hamadan, Iran.Email: alikhani@umsha.ac.ir

\begin{tabular}{|c|c|}
\hline & Abstract \\
\hline $\begin{array}{l}\text { Received: } 18.05 .2017 \\
\text { Accepted: } 10.09 .2017\end{array}$ & \multirow{3}{*}{$\begin{array}{l}\text { Background and Objective: Campylobacter is a common type of bacteria } \\
\text { in humans and poultry, which generally accounts for various diseases in } \\
\text { humans, such as gastroenteritis. The poultry digestive system contains a high } \\
\text { level of these bacteria. The aim of this study was to evaluate the prevalence } \\
\text { of } C \text {. jejuni and } C \text {. coli in the poultry liver packed for marketing and } \\
\text { determine the antibiotic resistance of the isolates. } \\
\text { Materials and Methods: This cross-sectional study was conducted in the } \\
\text { spring of } 2016 \text { in the city of Hamadan, Iran. A total of } 80 \text { samples of packed } \\
\text { chicken liver were collected from the stores supplying meat and poultry } \\
\text { products in Hamadan. The enrichment of the liver samples was performed in } \\
\text { brucella broth; subsequently, separation was carried out on Campylobacter } \\
\text { selective agar. The presence of bacteria was confirmed by the implementation } \\
\text { of chemical diagnostic tests and direct microscopic observation. Finally, the } \\
\text { antibiotic resistance of the isolates was tested using disk diffusion method. } \\
\text { Results: According to the results, Campylobacter had a prevalence rate of } \\
90 \%, 73.61 \% \text { and } 26.39 \% \text { of which were } C \text {. jejuni and } C \text {. coli, respectively. } \\
\text { Out of the } 12 \text { antibiotic discs used in this study, the highest resistance ( } 79 \%) \\
\text { and sensitivity ( } 99 \% \text { ) rates were observed for cotrimoxazole (10 } \mu \text { g) and } \\
\text { gentamycin }(10 \mu \mathrm{g} \text { ), respectively. } \\
\text { Conclusion: The packed poultry liver in Hamadan had a relatively high } \\
\text { prevalence of } C \text {. jejuni and } C \text {. coli. Therefore, the consumers should be } \\
\text { careful about the cooking time and using this food. Accordingly, they can } \\
\text { prevent the dissemination of this bacteria by cooking the liver at a } \\
\text { temperature of above } 70^{\circ} \mathrm{C} \text { for } 20 \text { min and properly washing the devices } \\
\text { before cooking this product. Additionally, the elderly, children, and those } \\
\text { with immunodeficiency are recommended to avoid eating poultry liver. } \\
\text { Keywords: Campylobacter coil; Campylobacter jejuni; Gastroenteritis; Poultry }\end{array}$} \\
\hline $\begin{array}{l}\text { How to Cite this Article: } \\
\text { Saadatmand A, Alikhani MY, } \\
\text { Habibipour R, Heshmati A. Anti- } \\
\text { biotic Resistance and Prevalence } \\
\text { of Campylobacter jejuni and } \\
\text { Campylobacter coli in Poultry } \\
\text { Liver in Hamadan, Iran. Sci J } \\
\text { Hamadan Univ Med Sci. 2017; } \\
\text { 24(3): 252-258. DOI: } 10.18869 / \\
\text { acadpub.ajcm.24.3.252. }\end{array}$ & \\
\hline & \\
\hline
\end{tabular}


do): 10.18869 /acadpub.ajcm.24.3.252

\title{
بررسى ميزان شيوع كمييلوباكترثزونى و كمييلوباكتر كلى دركبد طيور و تعيين مقاومت آنتى بيوتيكى ايزولهها
}

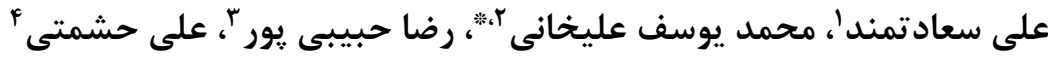 \\ ' دانش آموخته كارشناسى ارشد ميكروبيولوزى، واحد همدان، دانشكاه آزاد اسلامى، همدان، ايران

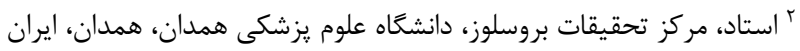

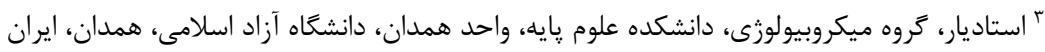

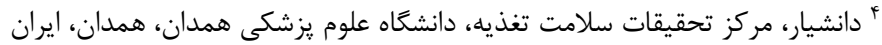
* نويسنده مسئول: محمد يوسف عليخانى، مركز تحقيقات بروسلوز، دانشعاه علوم يزشكى همدان، همدان، ايران. ايميل:ulikhani@umsha.ac.ir

\begin{tabular}{|c|c|}
\hline 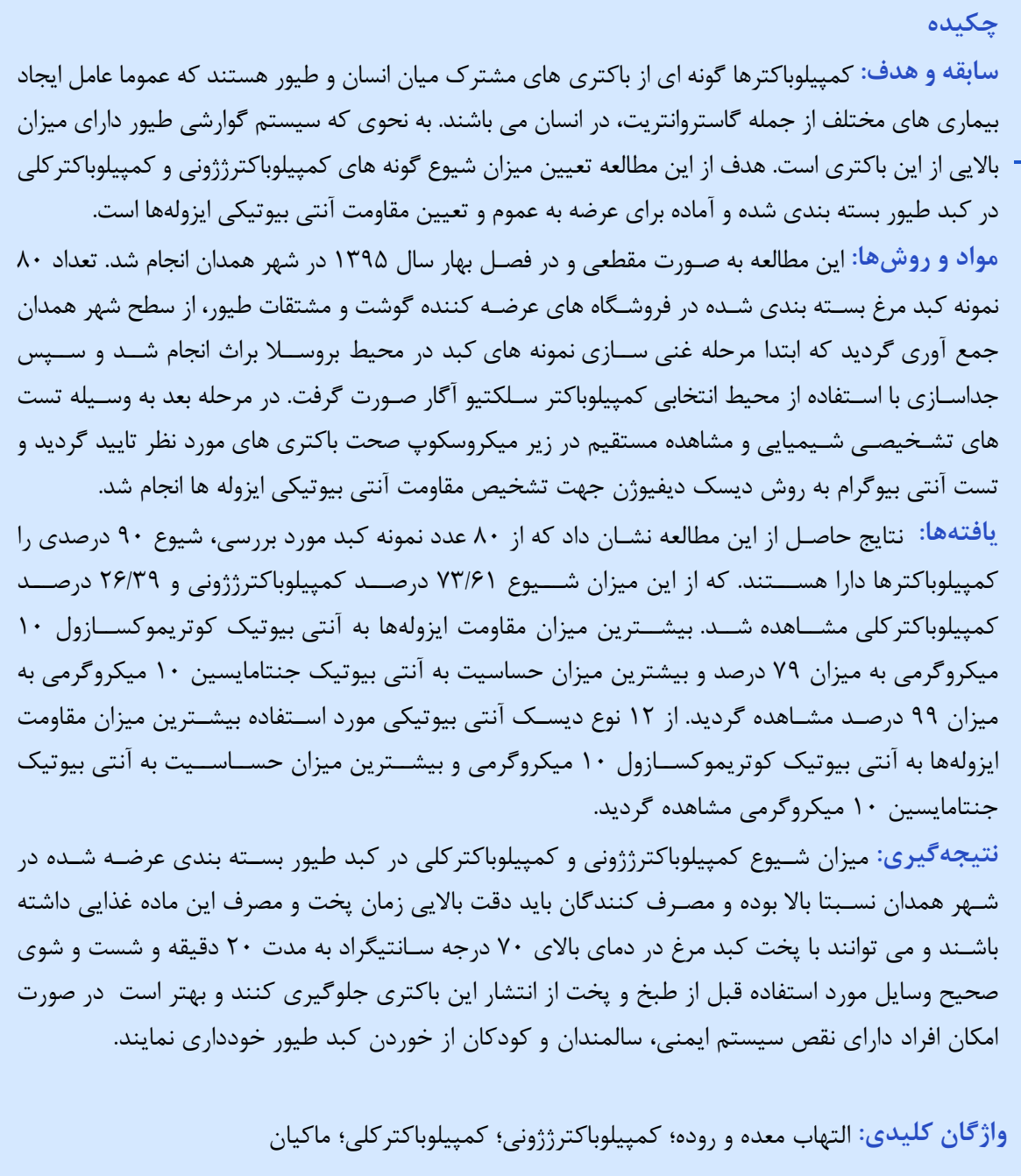 & 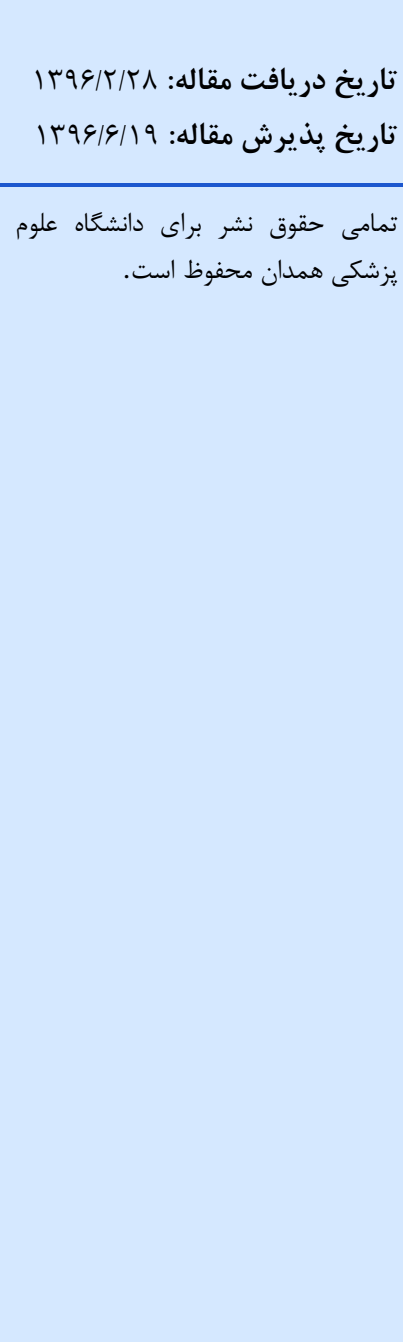 \\
\hline
\end{tabular}

سمينارى اين ميكرواركانيسمها به عنوان خانواده كمييلوباكترها

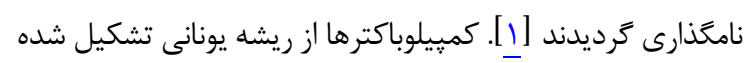

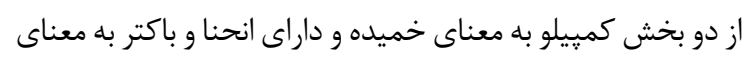

تئوبالداسميت درسال 1919 در حال بررسى علل سقط جنين -

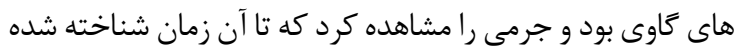

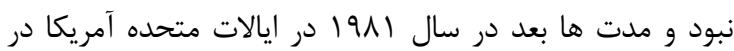


كه براى مصرف عموم در يخجال با دماى f أ درجه سانتى گراد

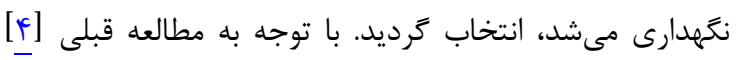

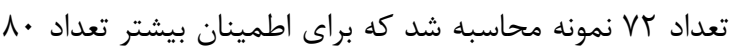
نمونه مورد مطالعه قراركرفت.

\section{غنى سازى نمونه هاى كبد}

نمونه بردارى از كبدها در شرايط استريل در آزمايشخاه انجام آندام

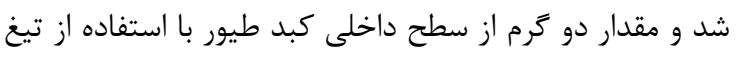
جراحى استريل به داخل لولههاى آزمايش حاوى محيط بران بروسلا

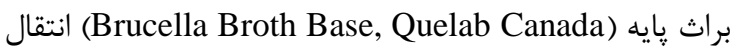
קيدا كرد. نمونها به درون جار منتقل و كاتاليزور و كازيك نوع (Anaerobic Gas Pack Type C, Merck Germany) C جهت تنفس باكترىها و ايجاد محيط ميكروائروفيليك در كنار

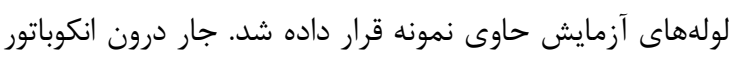

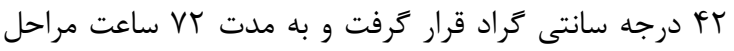
غنى سازى به روى باكترىهاى موجود در نمونهها انجام شد.

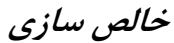

به كمك لوٍ استريل در كنار شعله از محيط بروسلا براث برداشته مى شد و به روى محيط كشت كمبيلوباكتر سلكتيو آكار بايه (Campylobacter Selective Agar Base, Quelab كشت خطى جهت كرفتن يركنه هاى تك، انجام مى شد (Canada كه اين محيط ها داراى مكمل هاى اسكيرو (Campylobacter و (Selective Supplement Skirrow, Quelab Canada همجنين داراى ه درصد خون دفيبرينه كوسفند بودند. سيس بار

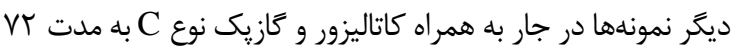

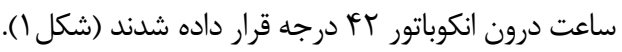

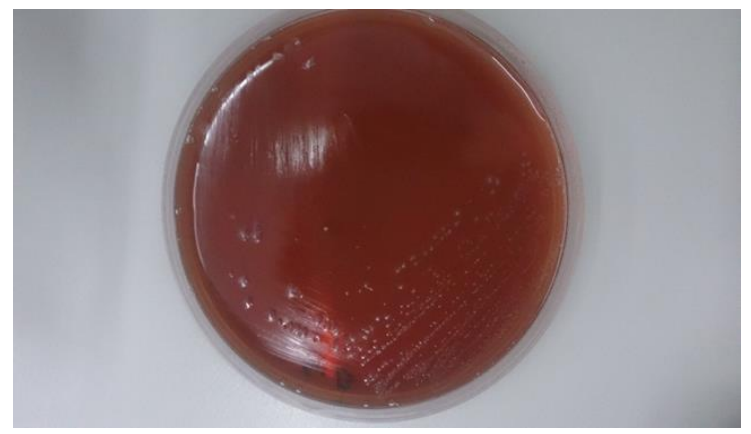

شكل ا: كميبيلوباكترهاى رشد يافته به روى محيط كميبيلوباكتر سلكتيو آكار به همراه خون

تشخيص و شناسا ييى

جهت شناسايى باكترىهاى رشد يافته به روى محيط كشت

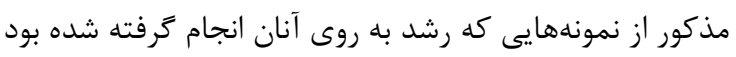

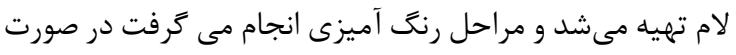

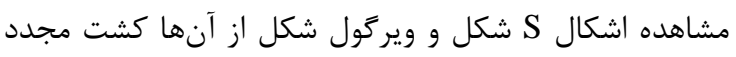

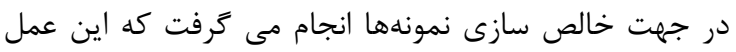

ميلهاى است. كمبيلوباكترها كَرم منفى مى باشند و هاكَ ندارند به

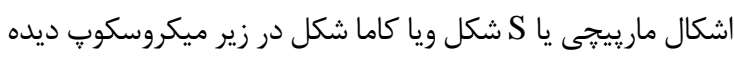

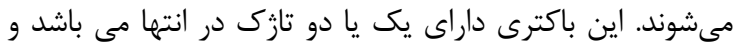

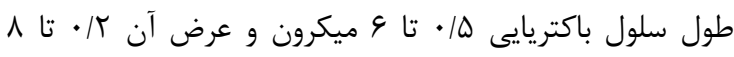

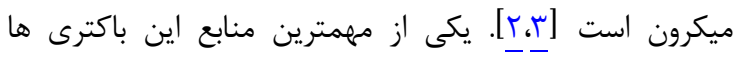

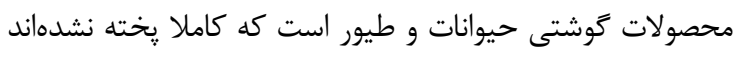

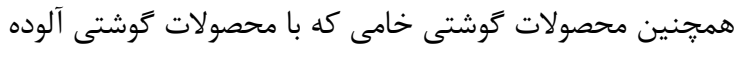

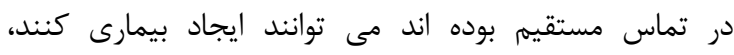

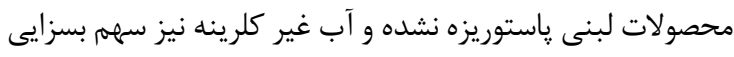

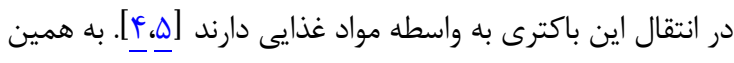

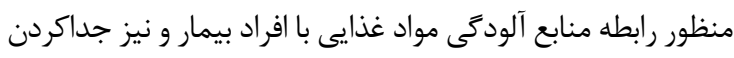

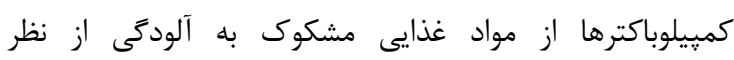

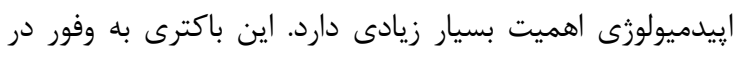

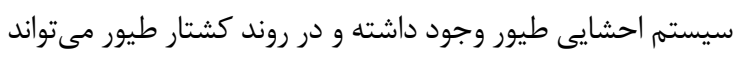

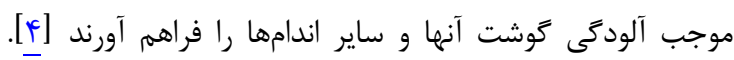

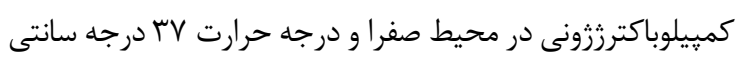

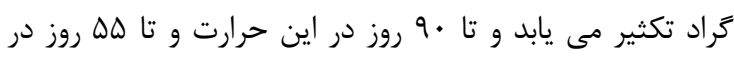

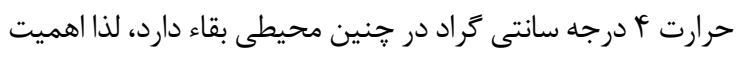

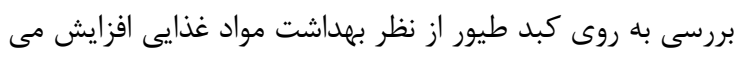

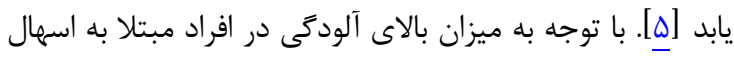

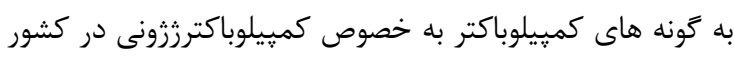

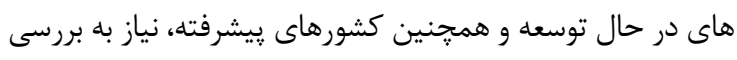

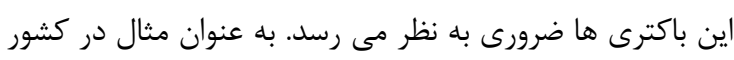

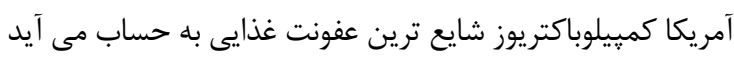

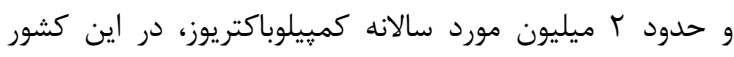

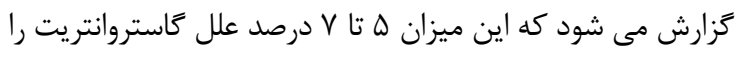

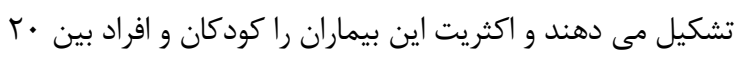

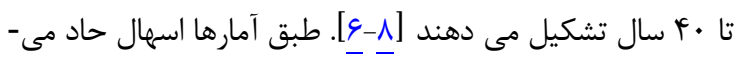

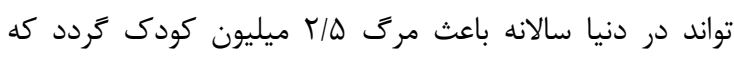

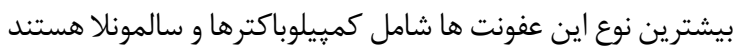

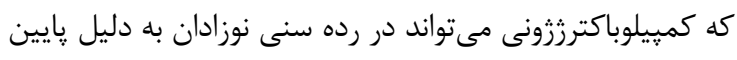

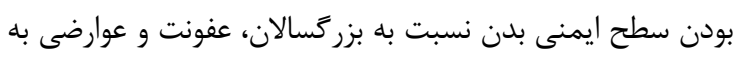

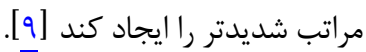

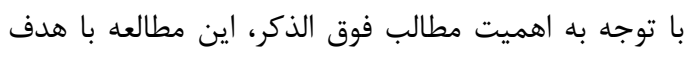

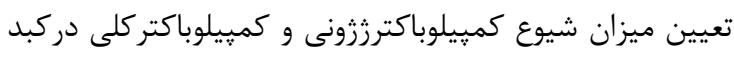

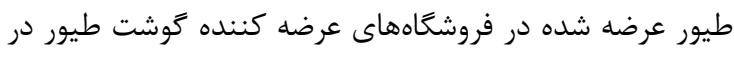

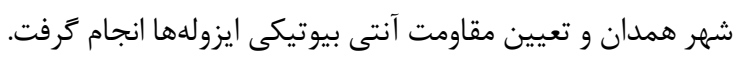

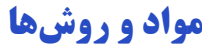

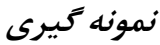

اين مطالعه به صورت مقطعى در بهار سال هوبا إندر شهر

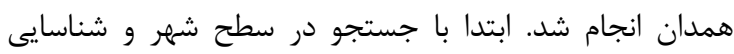

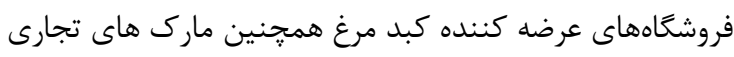

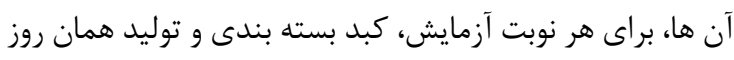


نمونه مورد مطالعه بود و زمانيكه در لوله آزمايش تغيير رنكى ديده

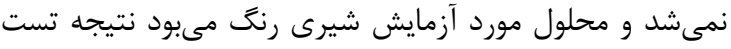

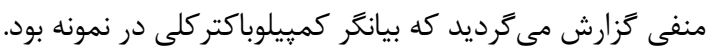

\section{تست آنتى بيوكرام}

در جهت انجام تست آنتى بيوگرام به روش رئ ديسك ديفيوزن، كشت باكترىها به روى محيط مولر هينتون آكار انجام پذيرفت (Mueller-Hinton Agar, Merck Germany) و تعداد • ا ديسك آنتى بيوتيكى (Padtan Teb, Iran) شامل

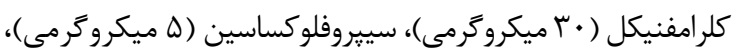

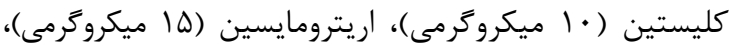

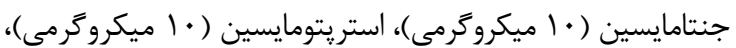

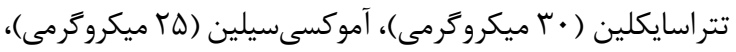

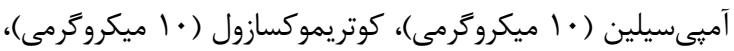

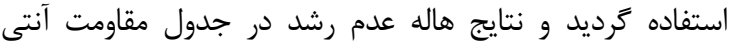
بيوتيكى CLSI بررسى كرديدند [•l].

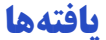

تعداد • ^ نمونه كبد مورد ارزيابى و مطالعه قرار گرفت كه از اين

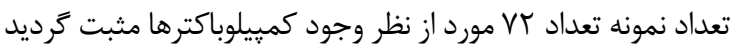

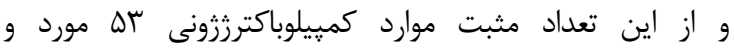

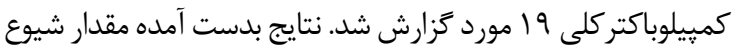

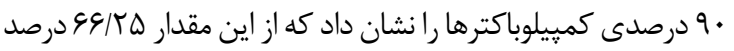

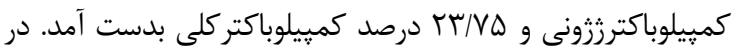

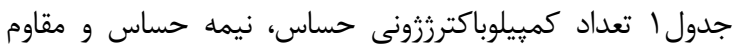

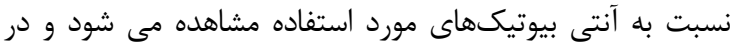
جدول r اين مقادير براى كمييلوباكتركلى مورد بررسى قرار كرفته نئه

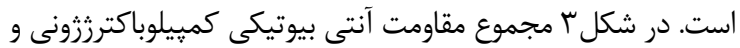

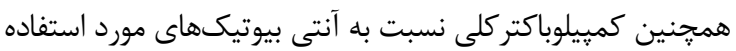
مورد مقايسه قرار زرفتهاند.
بين ץ تا ه دوره براى به دست آوردن گرگَنه خالص به طول مى

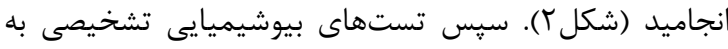

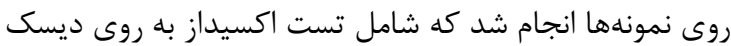

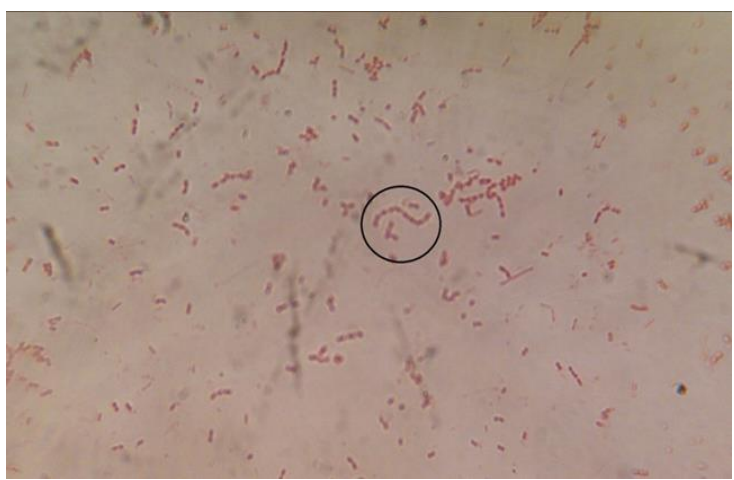

شكل r: فرم وير گول شكل و S شكل كمبيلوباكتر در زير

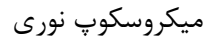

تست كاتالاز و استفاده از (Padtan Teb Oxidase Test, Iran) ديسكهاى آنتى بيوتيكى ) Padtan Teb Antibiogram Test,

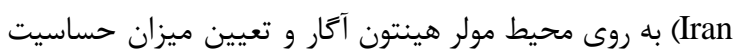

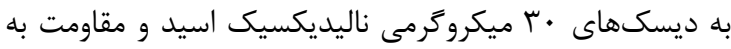

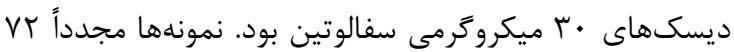

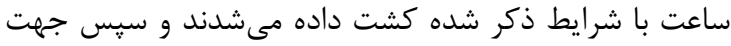
انجام تست هيدروليز هييورات با معرف نين هيدريدين اقدام مى شد كه به لولههاى حاوى هييورات سديم يك هير درصد ير گنهها اضافه ئ (Sodium Hippurate, Merck Germany) مى گرديد كه يس از اضافه كردن معرف نين هيدريدين (Reagent Ninhydrin, Merck Germany) مثبت و كمييلوباكتر كلى نتيجه تست منفى دارد و افتراق بين اين

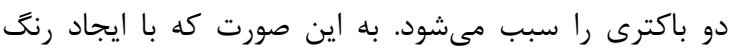

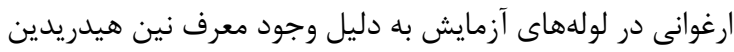

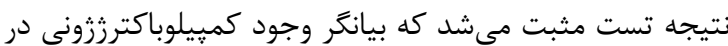

جدول ا: فراوانى ايزولههاى كميِيلوباكترثزونى حساس، نيمه حساس و مقاوم

\begin{tabular}{|c|c|c|c|c|c|c|}
\hline \multicolumn{2}{|c|}{ مقاوم } & \multicolumn{2}{|c|}{ نيمه حساس } & \multicolumn{2}{|c|}{ حساس } & \multirow{2}{*}{ نام آنتى بيوتيك } \\
\hline درصد & تعداد & درصد & تعداد & درصد & تعداد & \\
\hline - & - & - & - & $1 \cdots$ & $\Delta r$ & جنتامايسين \\
\hline - & . & 4 & $r$ & $q 4$ & $\Delta \cdot$ & ناليديكسيك اسيد \\
\hline 4 & r & . & . & 94 & $\Delta \cdot$ & كلرامفنيكل \\
\hline 4 & r & $\Lambda$ & r & 19 & is & ريترومايسين \\
\hline rI & 11 & f & r & $V \Delta$ & r. & استريتومايسين \\
\hline r. & 1 . & 9 & $\Delta$ & VI & rᄉ & تتراسايكلين \\
\hline rq & 10 & Ir & V & $\Delta \Lambda$ & rI & سييروفلوكساسين \\
\hline 41 & Tr & r & 1 & $\Delta V$ & $r$. & آموكسىسيلين \\
\hline FF & r & v & f & fq & rq & آميىسيلين \\
\hline$V \Delta$ & f. & 4 & r & 19 & $1 \cdot$ & سفالوتين \\
\hline$\wedge$. & fr & 1. & $\theta$ & 1. & $\Delta$ & كليستين \\
\hline$\wedge r$ & fF & ir & v & r & r & كوتر يموكسازول \\
\hline
\end{tabular}




\begin{tabular}{|c|c|c|c|c|c|c|}
\hline \multicolumn{2}{|c|}{ مقاوم } & \multicolumn{2}{|c|}{ نيمه حساس } & \multicolumn{2}{|c|}{ حساس } & \multirow{2}{*}{ نام آنتى بيوتيك } \\
\hline درصد & تعداد & درصد & تعداد & درصد & تعداد & \\
\hline . & . & $\Delta$ & 1 & 90 & 11 & جنتامايسين \\
\hline$\Delta$ & 1 & 11 & r & $\Delta F$ & 19 & ناليديكسيك اسيد \\
\hline$\Delta$ & 1 & 19 & $r$ & vq & 10 & كلر امفنيكل \\
\hline 11 & r & 10 & r & VF & if & اريترومايسين \\
\hline rI & f & $\Delta$ & 1 & VF & If & استريتومايسين \\
\hline rq & $\Delta$ & 11 & $r$ & $4 \pi$ & ir & تتراسايكلين \\
\hline ru & v & 10 & $r$ & iv & 9 & سييروفلوكساسين \\
\hline Fr & 1 & 11 & $r$ & iv & 9 & آموكسىسيلين \\
\hline$\Delta r$ & 1. & 10 & r & rt & 4 & آميىسيلين \\
\hline sq & IT & 10 & $r$ & rI & f & سفالوتين \\
\hline sf & Ir & 10 & r & rI & r & كليستين \\
\hline 99 & Ir & re & $\Delta$ & $\Delta$ & 1 & كوتريموكسازول \\
\hline
\end{tabular}

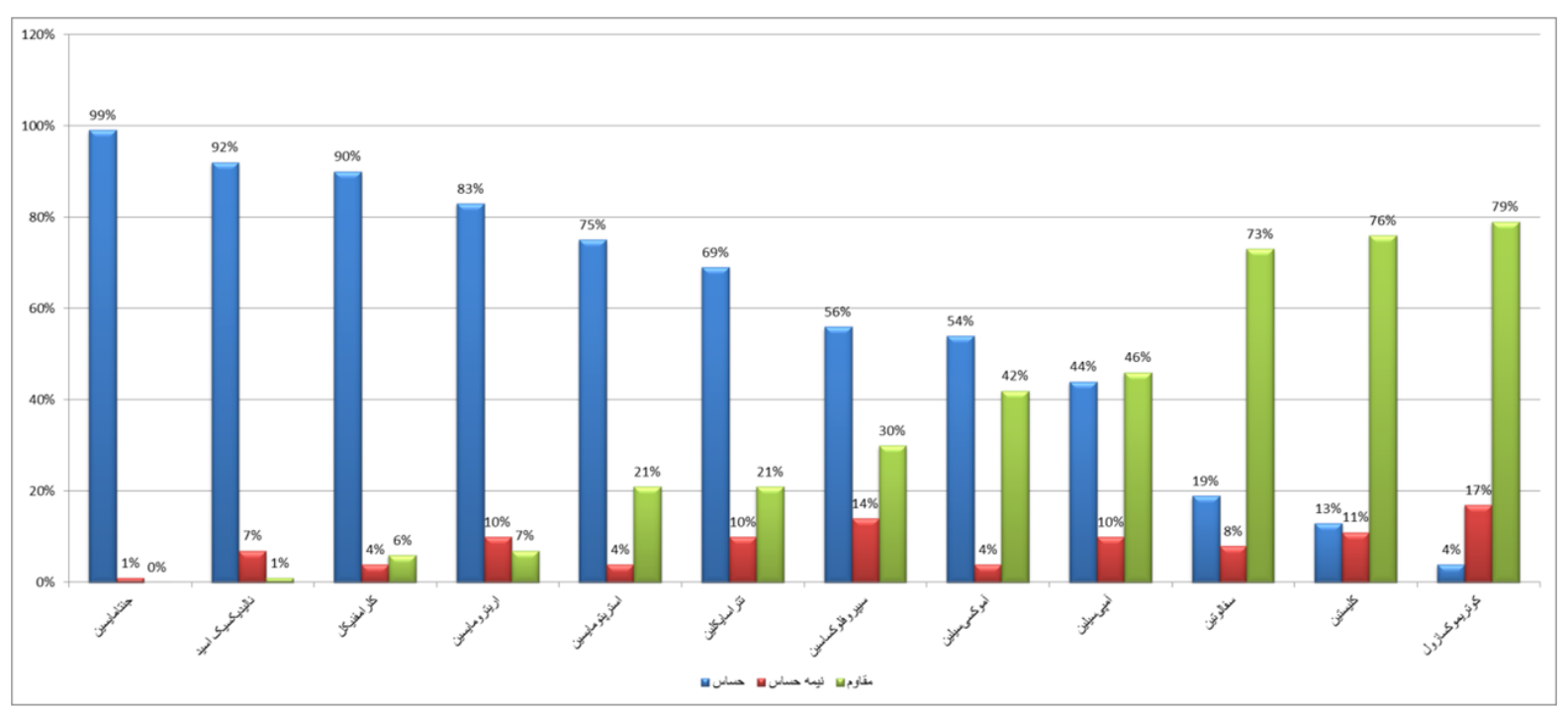

شكل بّ: درصد تاثير آنتى بيوتيكهاى مورد استفاده به روى كمييلوباكترززونى و كلى سلى

كمبيلوباكتريوزيس در انسان توسط كمييلوباكترززونى و جهار

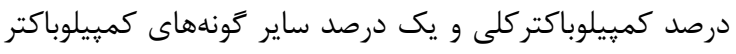
[ايجاد مى كردد [برا]

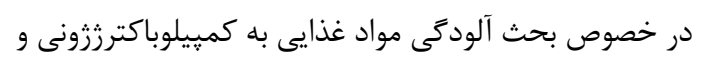

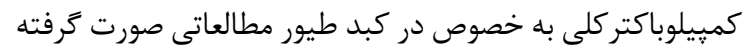

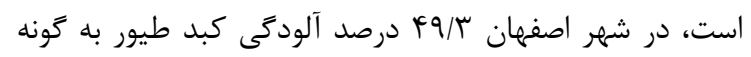

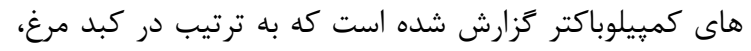

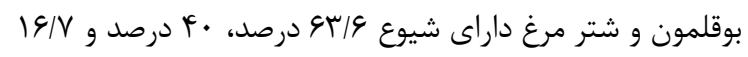

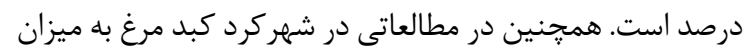

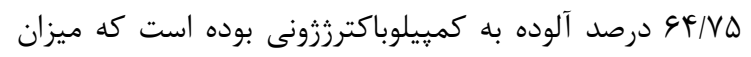

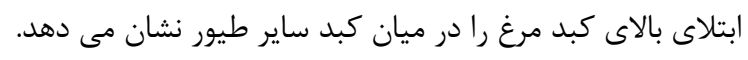

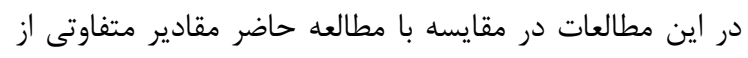

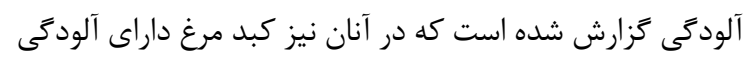

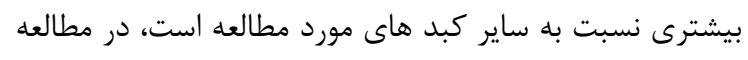

بهداشت مواد غذايى در سراسر جهان سعى در كنترل و و مباد

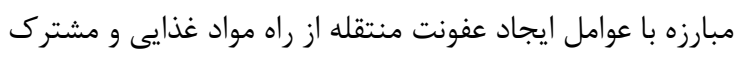

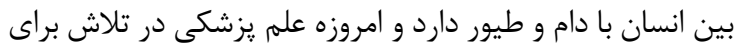

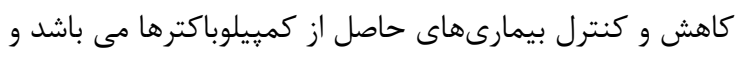
سعى در كنترل و ريشه كنى اين بيمارىها دارد. بيمارى إهاى

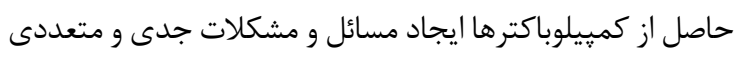

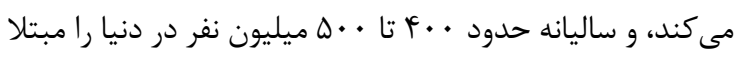

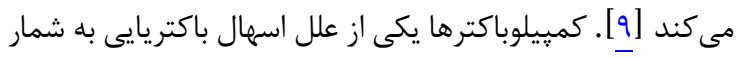

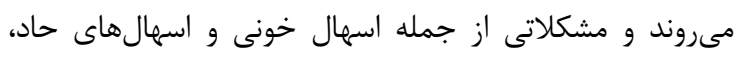

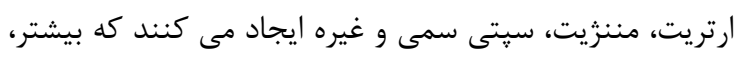

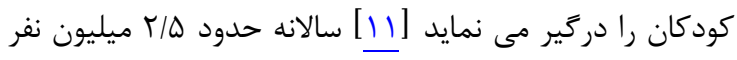

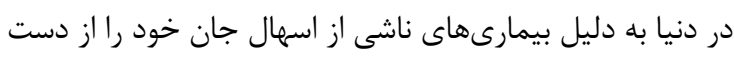

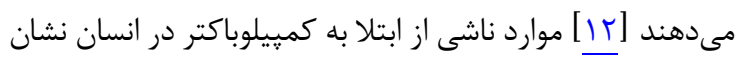

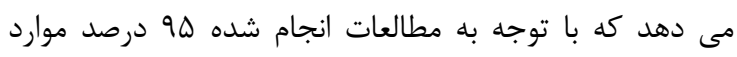


روى كمييلوباكترززونى و كمييلوباكتركلى بيانگر مقاومت نسبتا

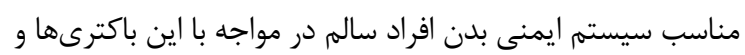

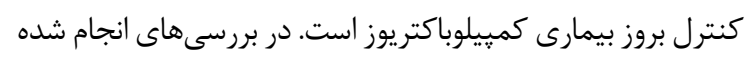

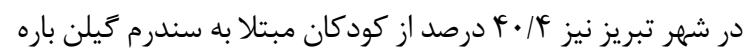

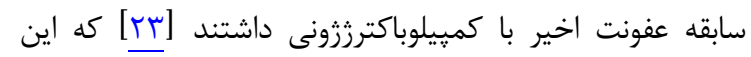

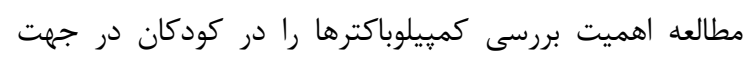
جلوكيرى از ابتلا به بيمارى سندرم كيلن باره بيشتر ميى كند زيرا

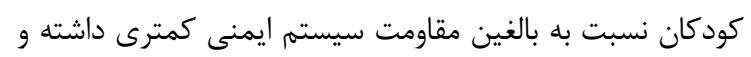

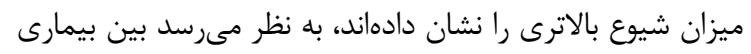

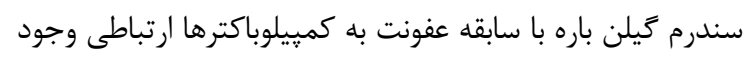

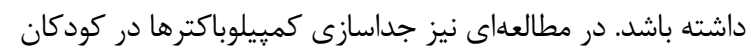

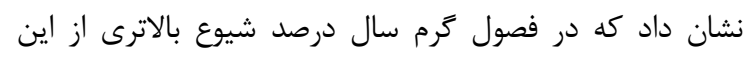

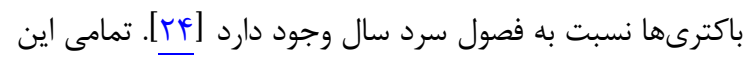

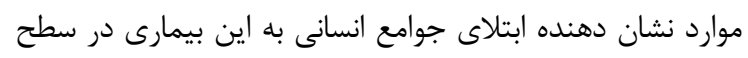

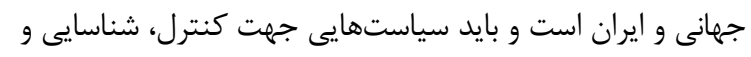

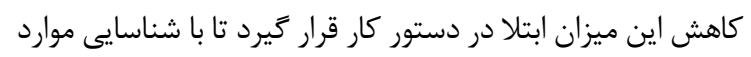

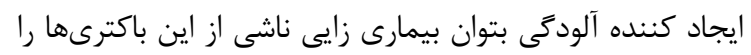

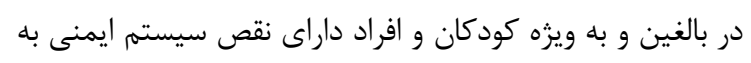
ميزان قابل توجهى كاهش داد. ساير مطالعات انجام شده در ايران

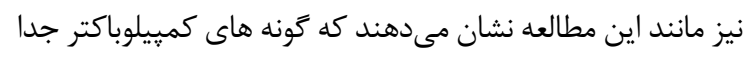

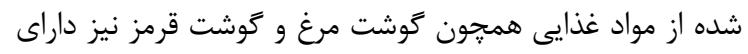

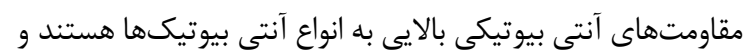

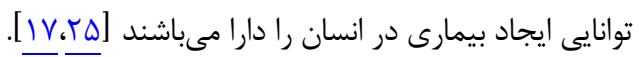

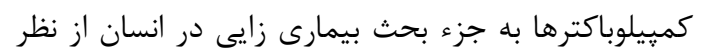

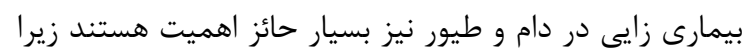

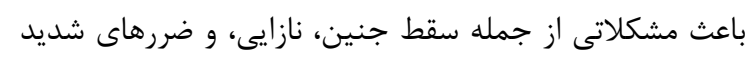

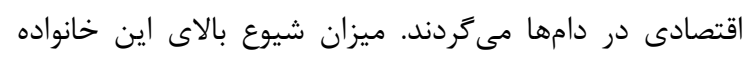

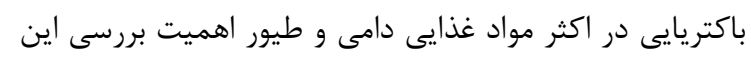

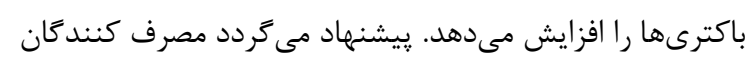

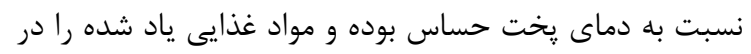

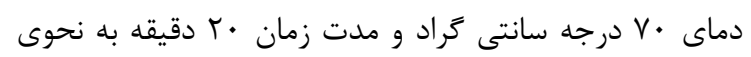

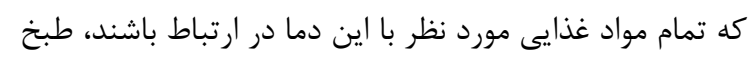

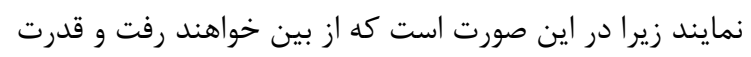
بيمارى زايى خود را از دست خواهند داد. توصيه اكيد مى خى رود

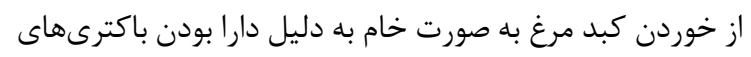

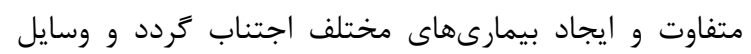

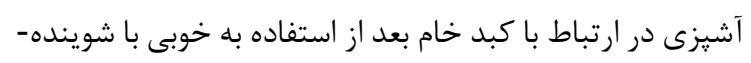

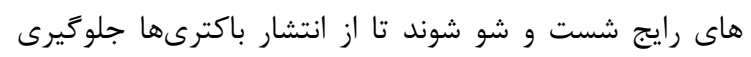
بعمل آيد.

\section{نتيجه كيرى}

اين مطالعه نشان داد كه درصد شيوع كمييلوباكترها در

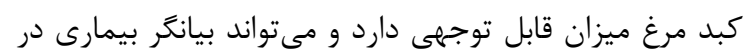

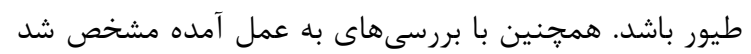

حاضر نيز اين ميزان شيوع بالاست كه اين مورد اهميت بررسى

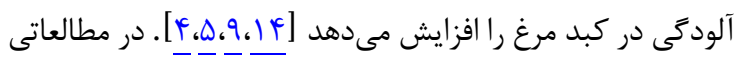

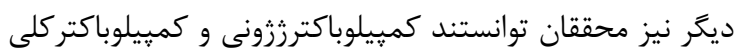

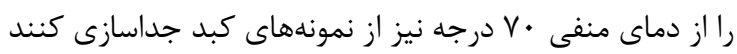

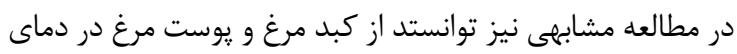

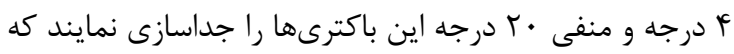

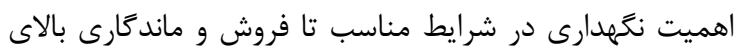

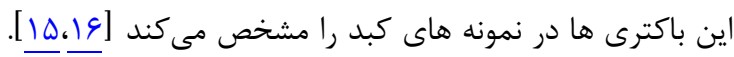

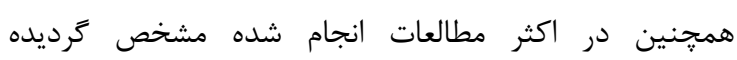

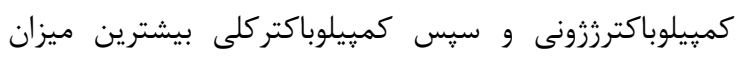

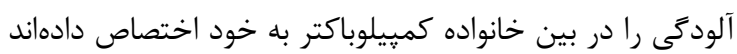

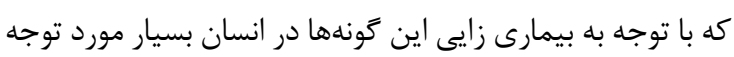
قرار مى

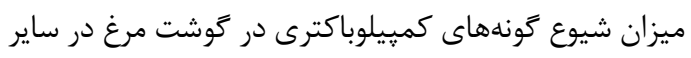
كشورها مانند كانادا ع/4/

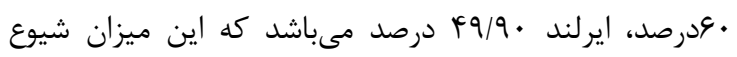

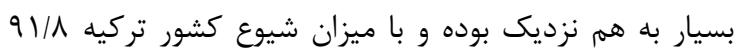

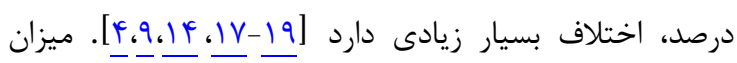
شيوع بدست آمده در اين مطالعه نيز شباهت زيادى بداد به ميزان

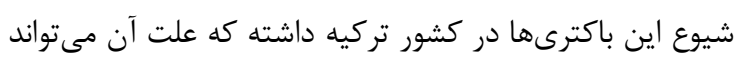

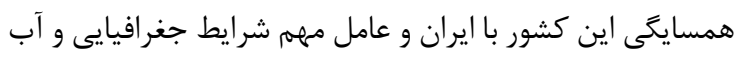

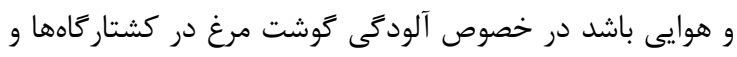
وجود اين باكترى در آب مورد استفاده در كشتاركاهها نيز

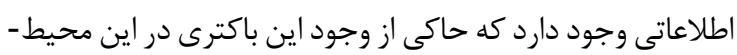

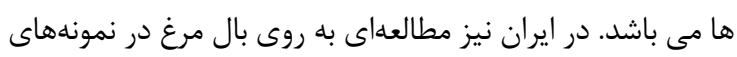

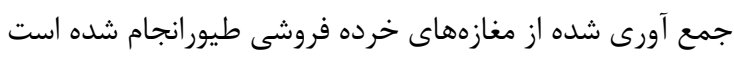

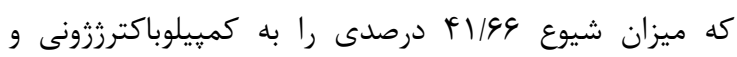

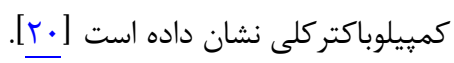

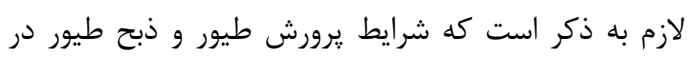

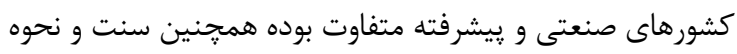

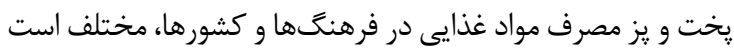

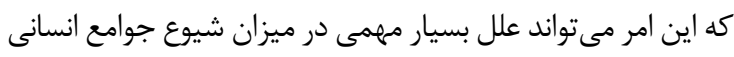

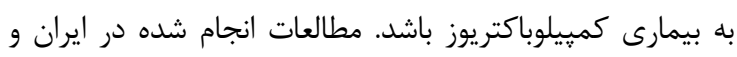

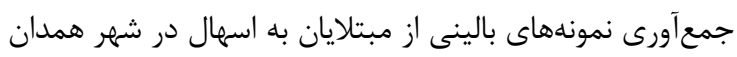

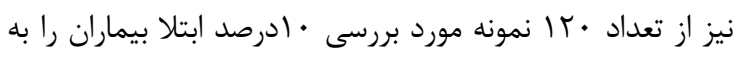

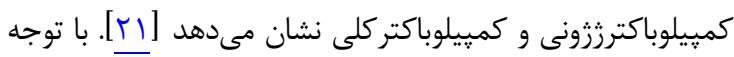
به نتايج بدست آمده در اين مطالعه و مقايسه با نتايج بدست كمئ آمده

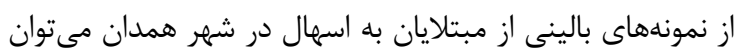

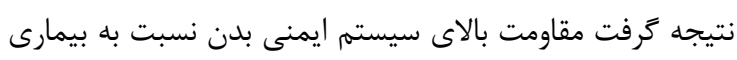

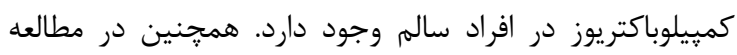

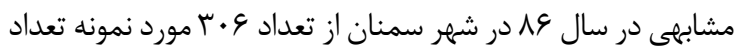

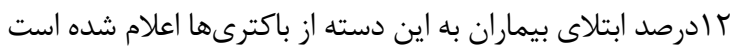

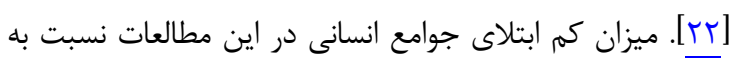

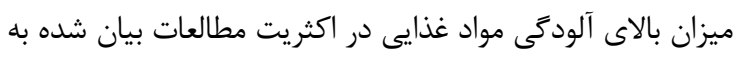




$$
\begin{aligned}
& \text { اين باكترى ها و قدرت بيمارى زايى آنان دارد [YY،r]. } \\
& \text { تشكر و قلرو قاذى } \\
& \text { اين مقاله بركرفته از پايان نامه كارشناسى ارشد ميكروبيولوزى }
\end{aligned}
$$

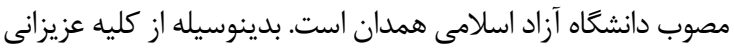

$$
\begin{aligned}
& \text { كه در انجام آن تقبل زحمت نموده اند قدرانى مى نماييمه. ضمناً }
\end{aligned}
$$

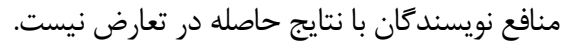

\section{REFERENCES}

1. Zoghi E. Campylobacteriosis in humans and animals. Tehran, Iran: Jahade Deneshgahi Press; 1990. P. 7-145. [Persian]

2. Mehdizadeh M, Eskandari S. The role of campylobacter jejuni in campylobacteriosis. J Kerman Univ Med Sci. 2009;16(2):188-96. [Persian]

3. Bennett JE, Dolin R, Blaser MJ. Principles and practice of infectious diseases. $8^{\text {th }}$ ed. NewYork: Saunders; 2015. P. 2485-93.

4. Shakerian A, Rokni N, Sharifzadeh A, Alagha S, Talebian R. Campylobacter jejuni as a potential pathogen in liver of broilers chickens in slaughtered \& retail market broilers in Shahr e Kord Iran. Iran J Food Sci Technol. 2005;2(1):43-50. [Persian]

5. Havaei SA, Pishva E, Tabibian A, Rabani M, Hagh SF, Narimani T. Cytolethal distending toxin (CDT) produced by campylobacter jejuni and campylobacter coli isolated from chikens by tissue culture method in isfahan. Iran $J$ Med Microbiol. 2007;1(3):17-23. [Persian]

6. Montville TJ, Matthews KR. Food microbiology an introduction. Washington DC: ASM Press; 2005. P. 101-9.

7. European Food Safety Authority. Campylobacter in animals and foodstuffs. EFSA J. 2005;173:1-10.

8. Rieman HP, Cliver DO. Foodborne disease. $2^{\text {nd }}$ ed. London: Academic Press; 2002. P.103-9.

9. Fani M, Mokhtarian D, Mohsenzadeh M, Ghahramani M, Moshki M. Detection and identification of campylobacter jejuni and campylobacter coli from poultry carcasses slaughtered in gonabad poultry slaughterhouse. Horizon Med Sci. 2009;15(2):30-5. [Persian]

10. Wayne PA. Clinical and laboratory standards institute. Performance standards for antimicrobial susceptibility testing. Wayne, PA: CLSI; 2015.

11. Tenakate TD, Stafford RJ. Risk factors for Campylobacter infection in infants and young children a matched case control study. Epidemiol Infect. 2001;127(3):399-404. PMID: 11811871

12. Marcus R. New information about pediatric foodborne infections the view from foodnet. Curr Opinion Pediatr. 2008;20(1):79-84. PMID: 18197044 DOI: 10.1097/MOP.0b013e3282f43067

13. National Advisory Committee on Microbiological Criteria for Foods. Analytical utility of campylobacter methodologies. J Food Prot. 2007;70(1):241-50. PMID: 17265889

14. Rahimi E. Campylobacter spp. contamination of chicken meat and by-products in Shahrekord, Iran. Sci Res Iran Veterinary J. 2012;9(1):30-6. [Persian]

15. Ivić-Kolevska S, Miljković-Selimović B, Kocić B, Kolevski G. Survival of campylobacter jejuni and campylobacter coli in chiken liver at frozen strogae temperetures. J Hyg Engin Des. 2012;579(835):10-15

$$
\begin{aligned}
& \text { اين باكترىها درحال تغيير و ايجاد مقاومت به برخى از آنتى } \\
& \text { بيوتيك ها هستند. } \\
& \text { بهتر است افراد داراى نقص سيستم ايمنى كودكان و } \\
& \text { سالمندان از مصرف مواد غذايى مشكوك به كمييلوباكترها } \\
& \text { خوددارى كنند و در صورت استفاده از اين مواد غذايى شرايط }
\end{aligned}
$$

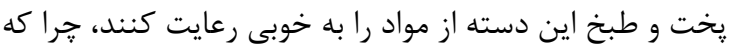

$$
\begin{aligned}
& \text { نحوه صحيح يخت و طبخ تاثير بسزايى درجلوگيرى از انتقال }
\end{aligned}
$$

16. Kocic B, Ivic Kolevska S, Miljkovic Selimovic B, Milosevic Z. Survival of Campylobacter jejuni in chicken meat chicken skin and chicken liver at low temperatures. Bratisl Lek Listy. 2012;113(6):354-6. PMID: 22693971

17. Soltan DM, Sanaei M, Taremi M, Moez AS, Edalatkhah H, Azimirad M, et al. Prevalence and antimicrobial resistance pattern of thermophilic campylobacter spp jejuni and coli isolated from beef and raw chicken in Tehran. J Zanjan Univ Med Sci. 2009;17(68):85-92. [Persian]

18. Taremi M, Mehdi Soltan Dallal M, Gachkar L, MoezArdalan S, Zolfagharian K, Reza Zali M. Prevalence and antimicrobial resistance of Campylobacter isolated from retail raw chicken and beef meat Tehran Iran. Int J Food Microbiol. 2006;108(3):401-3. PMID: 16481059 DOI: $10.1016 /$ j.ijfoodmicro.2005.12.010

19. Granić K, Krčar D, Uhitil S, Jakšić S. Determination of Campylobacter spp in poultry slaughterhouses and poultry meat. Vet Arhiv. 2009;79(5):491-7.

20. Hosseinzadeh S, Mardani K, Aliakbarlu J, Ghorbanzadehghan M. Occurrence of Campylobacter in chicken wings marketed in the northwest of Iran. Int Food Res J. 2015; 22(1):41-5.

21. Rastyani S, Alikhani MY, Sedighi I, Kazemi S, Kohan HF, Arabestani MR. Campylobacter jejuni and Campylobacter coli in children with acute diarrhea in Health Centers of Hamadan Iran. Avicenna $J$ Clin Microb Infect. 2015;2(4):e29791. DOI: 10.1007/s00436-017-5376-3

22. Irajian G, Jazayeri Moghadas A, Beheshti A, Salehian A, Monem M, Moghoddas F. Prevalence of Campylobacter jejuni samples from patientsreferred to Semnan public health centers in 2007. Iran J Med Microbiol. 2008;1(4):35-9. [Persian]

23. Barzegar M, Kargar Maher MH, Pour Hosein D, Bonyadi MR. Clinical and laboratory features of childhood guillainbarre syndrome associated with campylibacter jejuni infection. Pejouhandeh. 2010;14(6):307-12. [Persian]

24. Soltan Dallal MM, Golkarieh N. Campylobacter infection in children. J Urmia Univ Med Sci. 2000;11:196-200. [Persian]

25. Dabiri H, Aghamohammad S, Goudarzi H, Noori M, Hedayati MA, Ghoreyshiamiri SM. Prevalence and antibiotic susceptibility of Campylobacter species isolated from chicken and beef meat. Int J Enteric Pathog. 2014;2(2):e17087.

26. Parry A, Fearnley E, Denehy E. Surprise outbreak of Campylobacter infection associated with chicken liver pate at a surprise birthday party, Adelaide, Australia, 2012. Western Pac Surveill Response J. 2012;3(40):16-9. PMID: 23908933 DOI: 10.5365/WPSAR.2012.3.4.011

27. Whyte R, Hudson JA, Graham C. Campylobacter in chicken livers and their destruction by pan frying. Lett Appl Microbiol. 2006;43(6):591-5. PMID: 17083702 DOI: 10.1111/j.1472-765X.2006.02020.x 